\title{
EFEKTIVITAS SEDIAAN SALEP EKSTRAK BUNGA KECOMBRANG (Etlingera elatior) TERHADAP PENYEMBUHAN LUKA INSISI PADA TIKUS \\ (Rattus norvegicus)
}

\author{
Ratna Widyawati ${ }^{1}$, Olan Rahayu Puji Astuti Nussa ${ }^{1}$, Bernadeta Perwirawati Lepu Geli ${ }^{1}$, \\ Miarsono Sigit ${ }^{*}$ \\ ${ }^{1}$ Fakultas Kedoktera Hewan, Universitas Wijaya Kusuma Surabaya \\ *Email: miarsono_sigit@uwks.ac.id
}

\begin{abstract}
Abtract
This study was conducted to determine the effect of ointment extract of kecombrang flower (Etlingera elatior) on healing incision wounds in white rats (Ratus norvegicus) in terms of the formation of wound scab, wound closure time and wound attachment. The experimental research used is Randomized complete design with 4 treatments with 6 replications. The treatments applied were P0 as a negative control, P1 (20\% kecombrang flower extract ointment), P2 (30\% kecombrang flower extract ointment) and P3 (40\% kecombrang flower extract ointment). Parameters of this study were the wound caropeng, wound closure time and wound attachment. The results obtained were different median values in the four groups with $p=0,000(p<0.05)$ in the Kruskal Wallis test. In the Mann Whitney test were significant differences between the groups of $20 \%$ kecombrang flower extract ointment concentration, $30 \%$ concentration and $40 \%$ concentration in the negative control group. The most effective result is ointment extract of kecombrang flower $20 \%$ on healing incision wounds.
\end{abstract}

Keywords: Kecombrang flowers, white rats, caropeng wounds, wound closure time, wound attachme

\section{PENDAHULUAN}

Luka merupakan kerusakan jaringan yang menyebabkan terganggunya proses selular normal dari tubuh, khususnya pada bagian kulit. Luka dibedakan berdasarkan penyebab lukanya, seperti luka bakar, luka sayat, luka tusuk dan lain sebagainya. Pada saat ini banyak dikembangkan obat-obat luka yang lebih cepat dalam menyembuhkan luka dan efek sampingnya ringan serta tidak menimbulkan iritasi (Sagala dkk, 2016).

Luka insisi adalah luka superfisial yang dibuat dengan cara menginsisi kulit menggunakan instrumen tajam seperti blade atau pisau (Sharma et al., 2011). Luka akan menimbulkan masalah jika penanganannya kurang baik sehingga menyebabkan luka kronis akibat tidak tercapainya proses penutupan luka yang sempurna (Sabirin dkk., 2013).

World Health Organization (WHO) merekomendasikan penggunaan obat tradisional termasuk herbal dalam pemeliharaan kesehatan masyarakat, pencegahan dan pengobatan penyakit, terutama untuk penyakit kronis, penyakit degeneratif dan kanker. Tanaman obat selain harganya relatif dapat dijangkau masyarakat, mudah diperoleh dan penggunaannya cukup praktis (Sulistiawati, 2011). Berbagai penelitian banyak dilakukan untuk membuktikan secara ilmiah khasiat tanaman obat. Salah satunya adalah tanaman kecombrang (Etlingera elatior).

Kecombrang (Etlingera elatior) merupakan salah satu jenis tananaman rempah-rempah asli Indonesia yang termasuk dalam familia Zingiberaceae yang secara tradisional sudah lama digunakan dan dimanfaatkan masyarakat sebagai obatobatan dan penyedap rasa (Syarief dkk., 2016).

Kandungan senyawa dalam bunga kecombrang antara lain, flavonoid, terpenoid, saponin dan tanin. Dari hasil fitokimia menunjukan bahwa adanya kandungan flavonoid, tanin, saponin, steroid, alkaloid 
dan terpenoid mampu untuk menyembuhkan luka (Wijaya, 2012).

\section{MATERI DAN METODE}

\section{Lokasi dan Waktu Penelitian}

Penelitian ini dilaksanakan di

Laboratorium Hewan Coba Fakultas Kedokteran Universitas wijaya Kusuma Surabaya.

\section{Metode Penelitian}

Jenis penelitian ini adalah penelitian eksperimental menggunakan Rancanagn Acak Lengkap (RAL) dengan teknik pengambilan sampel acak dengan 4

perlakuan dan 6 ulangan untuk masingmasing perlakuan. Penelitian ini bertujuan untuk mengetahui potensi salep ekstrak bunga kecombrang (Etlingera elatior) terhadap kesembuhan luka insisi pada tikus putih (Rattus norvegicus).

\section{Materi Penelitian}

Alat yang digunakan: timbangan analitik, penggaris, scalpel, blade, pinset, gunting, alat tulis, kamera, kandang tikus, tempat makan dan minumtikus.

Bahan yang digunakan: tikus putih jantan (Rattus norvegicus), bunga kecombrang (Etlingera elatior), etanol, alkohol, obat bius zoletil.

Ekstrak bunga kecombrang adalah ekstrak yang dihasilkan dari bunga kecombrang yang dikeringkan menggunakan metode ekstrasi dengan larutan etanol $96 \%$. Proses pembuatan ekstrak dimulai dikerjakan oleh tenaga ahli di Balai Penelitian dan Konsultasi Industri Surabaya.

Subjek yang digunakan untuk penelitian ini adalah tikus putih (Rattus norvegicus) jenis kelamin jantan usia 2-3 bulan dengan berat 150-200 gram. Besar sampel yang digunakan sebanyak 24 ekor tikus putih. Penelitian ini menggunakan 6 ekor tikus putih untuk setiap kelompok perlakuan dan setiap tikus diberi luka sayatan. Keempat perlakuan tersebut terdiri dari kontrol negatif yang tidak diberi perlakuan dan kelompok uji yang terdiri dari konsentrasi 20\%, 30\%, 40\% salep ekstrak bunga kecombrang. Kemudian diberikan salep ekstrak bunga kecombrang (Etlingera elatior) 1 kali sehari selama dua minggu, dan dilakukan pengamatan terhadap proses penyembuhan luka.

Analisis Data yang digunakan adalah dengan cara Kruskal-Wallis Test dan untuk menganalisa apakah terdapat perbedaan antara setiap perlakuan dilakukan uji Mann Whitney Test.

\section{HASIL}

Karopeng Luka

Tabel 1. Rata-rata nilai pembentukan karopeng menurut Kruskal Wallis Test.

\begin{tabular}{|c|c|c|}
\hline Perlakuan & $\mathbf{N}$ & Mean Rank \\
\hline P0 (Kontrol) & 6 & 17.50 \\
\hline P1 (Salep & 6 & 5.33 \\
\hline \multicolumn{3}{|l|}{ Ekstrak Bunga } \\
\hline \multicolumn{3}{|l|}{ Kecombrang } \\
\hline $20 \%)$ & & \\
\hline P2 (Salep & 6 & 12.25 \\
\hline \multicolumn{3}{|l|}{ Ekstrak Bunga } \\
\hline \multicolumn{3}{|l|}{ Kecombrang } \\
\hline 30\%) & & \\
\hline P3 (Salep & 6 & 14.92 \\
\hline \multicolumn{3}{|l|}{ Ekstrak Bunga } \\
\hline \multicolumn{3}{|l|}{ Kecombrang } \\
\hline 40\%) & 24 & \\
\hline & 24 & \\
\hline
\end{tabular}

Rata-rata nilai karopeng luka tertinggi terdapat pada tikus $\mathrm{P} 1$ yaitu 5,33 dan rata-rata nilai karopeng terendah terdapat pada bagian tikus tanpa perlakuan (P0) yaitu 17,50. Hasil ini didukung dengan Kruskal-Wallis Test dengan taraf signifikan lebih dari 0.05 $(\mathrm{P}<0,5)$ maka $\mathrm{H} 1$ diterima, sehingga dapat dikatakan bahwa terdapat pengaruh nyata salep ekstrak bunga kecombrang terhadap nilai karopeng tikus.

Tabel 2. Hasil Uji Mann Whitney

\begin{tabular}{|c|c|c|}
\hline & Kelompok & Asymp. Sig \\
\hline Kontrol & P1 $(20 \%)$ & 0,020 \\
\hline \multirow{2}{*}{ Negatif (P0) } & P2 (20\%) & 0,560 \\
\hline & P3 (30\%) & 0,317 \\
\hline \multirow[t]{2}{*}{ P1 $(20 \%)$} & P2 (20\%) & 0,300 \\
\hline & P3 $(40 \%)$ & $\underline{0,270}$ \\
\hline P2 (30\%) & P3 $(40 \%)$ & 0,386 \\
\hline
\end{tabular}

$* \mathrm{P}<0,05$ : Berpengaruh nyata

Berdasarkan tabel 2 hasil perbandingan dengan menggunakan uji Mann Whitney antara kelompok kontrol negatif (P0) dengan kelompok P1 (20\%) berbeda signifikan dengan nilai signifikan $0,020<0,05$ (p-value $<\alpha$ ), sedangkan antara kelompok negative (P0) dengan kelompok P2 (30\%) dan P3 
(40\%) tidak berbeda signifikan dengan nilai signifikansi $p$-value $>0,05$. Pada kelompok perlakuan P1 (20\%) tidak berbeda signifikan dengan P2 (30\%) dan P3 (40\%). Kelompok P2 (30\%) tidak berbeda signifikan dengan P3 $(40 \%)$.

\section{Waktu Penutupan Luka}

Tabel 3. Rata-rata nilai waktu penutupan luka menurut Uji Kruskal Wallis

\begin{tabular}{|c|c|c|}
\hline Perlakuan & $\mathbf{N}$ & Mean Rank \\
\hline P0 (Kontrol) & 6 & 7.25 \\
\hline P1 (Salep & 6 & 18.25 \\
\hline Ekstrak Bunga & & \\
\hline $\begin{array}{l}\text { Kecombrang } \\
20 \% \text { ) }\end{array}$ & 6 & 14.00 \\
\hline P2 (Salep & 6 & \\
\hline Ekstrak Bunga & & 10.50 \\
\hline $\begin{array}{l}\text { Kecombrang } \\
\text { 30\%) }\end{array}$ & 24 & \\
\hline P3 (Salep & & \\
\hline Ekstrak Bunga & & \\
\hline Kecombrang & & \\
\hline $40 \%)$ & & \\
\hline Total & & \\
\hline
\end{tabular}

Rata-rata nilai waktu penutupan luka tertinggi terdapat pada tikus tanpa perlakuan (P1) yaitu 18,25 dan rata-rata nilai waktu penutupan luka terendah terdapat pada bagian tikus yang diberikan perlakuan yaitu (P0) 7,25. Hasil ini didukung dengan KruskalWallis Test dengan taraf signifikan lebih dari $0.05(\mathrm{P}<0,5)$ maka $\mathrm{H} 1$ diterima, sehingga dapat dikatakan bahwa terdapat pengaruh nyata salep ekstrak bunga kecombrang terhadap nilai waktu penutupan luka.

Tabel 4. Hasil Uji Mann Whitney

\begin{tabular}{|c|c|c|}
\hline & Kelompok & Asymp. Sig \\
\hline Kontrol & P1 $(20 \%)$ & $\underline{0,006}$ \\
\hline \multirow[t]{2}{*}{ Negatif (P0) } & P2 $(20 \%)$ & $\underline{0,051}$ \\
\hline & P3 $(30 \%)$ & 0,546 \\
\hline \multirow[t]{2}{*}{ P1 (20\%) } & $\underline{\mathrm{P} 2}(20 \%)$ & 0,171 \\
\hline & P3 (40\%) & $\underline{0,730}$ \\
\hline P2 (30\%) & P3 (40\%) & 0,382 \\
\hline
\end{tabular}

$* \mathrm{P}<0,05$ : Berpengaruh nyata

Berdasarkan tabel 4 hasil perbandingan dengan menggunakan uji Mann Whitney antara kelompok kontrol negative (P0) dengan kelompok P1 (20\%) berbeda signifikan dengan nilai signifikan $0,006<0,05$ (p-value $<\alpha)$, antara kelompok negatif (P0) dengan kelompok P2 (30\%) berbeda signifikan sedangkan P3 (40\%) tidak berbeda signifikan dengan nilai signifikansi $p$ value $>0,05$. Pada kelompok perlakuan P1 (20\%) tidak berbeda signifikan dengan P2 (30\%) dan P3 (40\%). Kelompok P2 (30\%) tidak berbeda signifikan dengan P3 (40\%).

\section{Perlekatan Luka}

Tabel 5. Rata-rata nilai waktu perlekatan luka menurut Uji Kruskal Wallis

\begin{tabular}{lcc}
\multicolumn{1}{c}{ Perlakuan } & N & $\begin{array}{c}\text { Mean } \\
\text { Rank }\end{array}$ \\
\cline { 3 - 3 } P0 (Kontrol) & 6 & 17.00 \\
$\begin{array}{l}\text { P1 (Salep Ekstrak } \\
\text { Bunga Kecombrang } \\
\text { 20\%) }\end{array}$ & 6 & 5.50 \\
$\begin{array}{l}\text { P2 (Salep Ekstrak } \\
\text { Bunga Kecombrang } \\
\text { 30\%) }\end{array}$ & 6 & 12.42 \\
$\begin{array}{l}\text { P3 (Salep Ekstrak } \\
\text { Bunga Kecombrang }\end{array}$ & 6 & 15.08 \\
$\begin{array}{l}\text { 40\%) } \\
\text { Total }\end{array}$ & 24 & \\
\hline
\end{tabular}

Rata-rata nilai perlekatan luka tertinggi terdapat pada tikus $\mathrm{P} 1$ yaitu 5,50 dan rata-rata nilai perlekatan luka terendah terdapat pada bagian tikus yang tidak diberikan perlakuan (P0) yaitu 17,00. Hasil ini didukung dengan Kruskal-Wallis Test dengan taraf signifikan lebih dari $0.05(\mathrm{P}<0,5)$ maka $\mathrm{H} 1$ diterima, sehingga dapat dikatakan bahwa terdapat pengaruh nyata salep ekstrak bunga kecombrang terhadap nilai karopeng tikus.

\section{Tabel 6. Hasil Uji Mann Whitney}

\begin{tabular}{|c|c|c|}
\hline & Kelompok & $\begin{array}{c}\text { Asymp. } \\
\text { Sig }\end{array}$ \\
\hline \multirow{3}{*}{$\begin{array}{c}\text { Kontrol } \\
\text { Negatif } \\
(\mathbf{P 0})\end{array}$} & P1 (20\%) & 0,001 \\
\hline & P2 $(20 \%)$ & 0,248 \\
\hline & P3 $(30 \%)$ & 0,317 \\
\hline \multirow[t]{2}{*}{ P1 $(20 \%)$} & $\mathrm{P} 2(20 \%)$ & 0,580 \\
\hline & P3 (40\%) & 0,005 \\
\hline P2 (30\%) & P3 (40\%) & 0,523 \\
\hline
\end{tabular}

Berdasarkan tabel 6 hasil perbandingan dengan menggunakan uji Mann Whitney antara kelompok kontrol negatif (P0) dengan kelompok P1 (20\%) berbeda signifikan dengan nilai signifikan $0,001<0,05$ (p-value $<\alpha$ ), sedangkan antara kelompok negative (P0) dengan kelompok P2 (30\%) dan P3 $(40 \%)$ tidak berbeda signifikan dengan nilai signifikansi $p$-value $>0,05$. Pada kelompok 
perlakuan P1 (20\%) tidak berbeda signifikan dengan P2 (30\%) dan signifikan dengan P3 (40\%). Kelompok P2 (30\%) tidak berbeda signifikan dengan P3 (40\%).

\section{PEMBAHASAN}

Berdasarkan pengamatan terbentuknya karopeng, terlihat bahwa kelompok uji konsentrasi rendah (20\%) berpotensi mempercepat waktu penyembuhan luka karena pembentukan karopeng paling cepat terbentuk dibandingkan dengan kelompok uji konsentarsi sedang (30\%) dan konsentrasi tinggi (40\%) serta kontrol negatif. Pada uji konsentasi tinggi pada (40\%) awalnya dapat mempercepat pembentukan pengeringan pada luka namun pengeringan ini memicu pembentukan karopeng atau jaringan mati yang sangat keras dan tebal dan menempel erat pada permukaan luka yang dapat menghambat distribusi zat aktif dan absorbsi obat sehingga luka lebih lama sembuh.

Berdasarkan hasil penelitian untuk luka tertutup $100 \%$ pada penggunaan masingmasing formula juga menunjukan perbedaan waktu. Hal ini terlihat dari hasil analisis statistik Kruskal-wallis dengan tingkat signifikan $\alpha=0,05$, ini berarti terdapat perbedaan waktu penyembuhan luka $100 \%$ yang sangat berbeda nyata/ sangat signifikan dari penggunaan masing-masing formula. Diamana rata-rata waktu penyembuhan luka untuk konsentrasi $20 \%$ yaitu 18,25 untuk $30 \%$ yaitu 14,00 untuk $40 \%$ yaitu $10,50 \%$ dan untuk kontrol negatif 7,25.

Hasil analisis data menggunakan metode Mann-Whitney pada perlekatan luka menunjukan bahwa perbandingan antara kontrol negatif (P0) dengan P1 menunjukan adanya nilai signifikan $0,01<0,05$. Namun pada kontrol negatif (P0), P1 dan P2 dengan kelompok lainnya tidak menunjukan nilai signifikasi yang berarti bahwa tidak terdapat perbedaan dari masing-masing kelompok perlakuan pada pengamatan perlekatan luka. Karena pada dasarnya setelah terjadinya luka, respon dari tubuh sudah mampu membuat luka itu menutup dengan sendirinya, tanpa diberikan pengobatan apapun (Guo dan Dipietro, 2010).

Mekanisme percepatan penyembuhan luka sayat pada tikus bukan dari kemampuan antibakteri tetapi lebih kepada kandungan kompleks ekstrak bunga kecombrang yang mengandung kombinasi flavanoid, terpenoid, saponin dan tanin yang saling menunjang. Diduga kandungan yang berperan aktif dalam peyembuhan luka yaitu adanya kandungan saponin. Dimana saponin dapat berperan sebagai antimikroba sehingga mencegah infeksi yang berat pada luka akibat mikroorganisme (Rachmawati, 2007).

$\mathrm{Hal}$ inilah yang menyebabkan pendarahan cepat berhenti ketika luka sayatan diberikan salep ekstrak bunga kecombrang setelah diinsisi (Noorhamdani dkk., 2012). Sedangkan tanin mempunyai fungsi sebagai adstringen yang mampu menciutkan pori-pori pada kulit, mempercepat pengerasan pada kulit, menghentikan eksudat dan pendarahan yang ringan, sehingga mampu menutupi luka dan mencegah pendarahan pada luka (Rahman, 2017).

\section{KESIMPULAN}

Berdasarkan penelitian yang dilakukan dapat disimpulkan bahwa Salep ekstrak bunga kecombrang (Etlingera elatior) memiliki efektifitas dalam menyembuhkan luka sayat pada tikus putih (Rattus norvegicus). Konsentrasi optimum salep ekstrak bunga kecombrang (Etlingera elatior) yang dapat menyembuhkan luka sayat pada tikus putih (Rattus norvegicus) dalam bentuk sediaan salep adalah $20 \%$.

\section{REFERENSI}

Guo, S. and L.A. DiPietro. 2010. Factors Affecting Wound Healing. Journal of Dental Research, US National Library of Medicine National Institutes of Health.

Noorhamdani, As., R. Setyohadi, Akmal Fawzi Y.U. 2012. Uji Efektifitas ekstrak daun binahong (Anredera cordifolia(Ten.)Steenis) sebagai antimikroba terhadapbakteri Klebsiella pneumoniae sesara In Vitro.Pendidikan Dokter Fakultas Kedokteran Universitas Brawijaya. Malang. 
Sabirin, I.P.R., A.M. Maskoen, dan B. S. Hernowo. 2013. Peran Ekstrak Etanol Topikal Daun Mengkudu (Morinda citrifolia) pada Penyembuhan

Sagala J. P., Wisnu C. P., Rolan R. 2016. Pengaruh Ekstrak Etanol Bunga Kecombrang(Etlingera elatior) Terhadap Penyembuhan Luka pada Tikus Putih (Rattus novergicus). Prosiding Seminar Nasional Tumbuhan Obat Indonesia Ke- 50. Samarinda, $20 \quad-21$ April 2016. Hal 243-24.

Sharma , M., B.S. Khajja, S. Jha, G.K.Mathur, dan V.N. Mathur. 2011. Forensic interpretation of injuries wounds found on the human body. J Punjad Acad Forensic Med Toxicol. 11(2):107-109.

Sulistiawati N. 2011. Pemberian Ekstrak Daun Lidah Buaya(Aloe vera) Konsentrasi $75 \%$ Lebih Menurunkan Jumlah Makrofag dari pada Konsentrasi 50\% dan 25\% pada Radang Mukosa Mulut Tikus Putih Jantan. [Tesis].Universitas Udayana. Denpasar. 51- 65.

Syarief R.A., Firdha S. dan Aktsar R.A. 2016. Rimpang Kecombrang (Etlingerelator jack) Sebagai Sumber Fenolik. Jurnal Fitofarmakan Indonesia. 2(2): 102- 106.

Wijaya, A. 2012. Pengaruh Pemberian Berbagai Coconut Oil Secara Topikal Terhadap Penyembuhan Luka Bakar Kimiawi pada Kulit Tikus Putih (Rattus novergicus) Terinduksi Asam Sulfat. Pendidikan Dokter FKIK8 (9).

Rachmawati S. 2007. Studi Makroskopik, dan Skrining Fitokimia Daun Binahong (AndrederA cordifolia (Ten) Skripsi tidak diterbitkan.Surabaya: fakultas Farmasi UNAIR Surabaya.

Rahman, A., 2017. Efek Salep Ekstrak Daun Kirinyuh Euphatorium odaratum) Terhadap Penyembuhan Luka Sayat Pada Ayam Petelur (Gallus leghorn). [Skripsi]. Program StudiKedokteran Hewan Fakultas Kedokteran Universitas

Hasanuddin. Makassar 